\title{
Effect of bioregulator Kelpak application in spring wheat on the occurrence of phytophagous insects
}

\author{
Wpływ stosowania bioregulatora Kelpak \\ na występowanie fitofagów w pszenicy jarej
}

\author{
Robert Lamparski ${ }^{1}$, Małgorzata Szczepanek ${ }^{2}$
}

\section{Summary}

The influence of different doses and application dates of the bioregulator Kelpak at successive spring wheat development stages (from shooting till milk-dough) on the phytophagous insect pest occurrence was tested. The field experiment was carried out in Mochełek near Bydgoszcz in 2011-2012. The number of insects caught with an entomological sweep net was compared in the twofactorial system: 1st factor - methods of the bioregulator Kelpak application: A1 - 2 l/ha at the beginning of tillering stage, $\mathrm{A} 2-1.5 \mathrm{l} /$ ha at tillering and $1.5 \mathrm{l} /$ ha at the shooting stage, $\mathrm{A} 3-2 \mathrm{l} /$ ha at the shooting stage, $\mathrm{K}-$ control (without Kelpak), $2 \mathrm{nd}$ factor spring wheat development stages: B1 - shooting, B2 - earing, B3 - flowering, B4 - milk-dough stage. In each of four replications of the treatment with an area of $18 \mathrm{~m}^{2}$, nine sweeps were made. The obtained results showed that the bioregulator Kelpak, irrespective of different doses and dates of application, reduced the total number of Thysanoptera, Hemiptera i Coleoptera. This was mainly related to the reduction of Sitobion avenae at the spring wheat developing stages: earing, flowering and milk-dough stage, as well as Thripidae and Oulema spp. larvae at the flowering stage.

Key words: spring wheat, insects, bioregulator Kelpak

\section{Streszczenie}

Badano wpływ stosowania bioregulatora Kelpak na liczebność szkodliwej entomofauny w pszenicy jarej, w kolejnych fazach jej rozwoju, od strzelania w źdźbło do dojrzewania. Doświadczenie polowe prowadzono w latach 2011-2012 w Mochełku koło Bydgoszczy. Liczebność entomofauny porównano przy pomocy analizy dwuczynnikowej: I - sposób i termin aplikacji bioregulatora Kelpak: 1 - na początku krzewienia - $2 \mathrm{l} /$ ha, 2 - po 1,5 I/ha w fazie krzewienia i strzelania w źdźbło, 3 - w fazie strzelania w źdźbło - 2 I/ha oraz 4 - kontrola (bez preparatu), II - faza rozwojowa pszenicy jarej: 1 - strzelanie w źdźbło, 2 - kłoszenie, 3 - kwitnienie i 4 - dojrzałość mleczno-woskowa. W każdym z czterech powtórzeń obiektu o powierzchni $18 \mathrm{~m}^{2}$ wykonano po 9 uderzeń czerpakiem entomologicznym. Stwierdzono, że bioregulator Kelpak aplikowany w dawce 2 l/ha w fazie krzewienia lub strzelania w źdźbło pszenicy jarej, jak również po 1,5 I/ha w obu tych fazach, ograniczał całkowitą liczebność fitofagów zaliczanych do Thysanoptera, Hemiptera i Coleoptera, w porównaniu do kontroli. Dotyczyło to przede wszystkim mszycy zbożowej w fazach rozwojowych: kłoszenie, kwitnienie i dojrzałość mleczno-woskowa, a także owadów zaliczanych do wciornastkowatych oraz larw skrzypionek w fazie kwitnienia pszenicy.

Słowa kluczowe: pszenica jara, owady, bioregulator Kelpak

Uniwersytet Technologiczno-Przyrodniczy w Bydgoszczy

Kordeckiego 20, 85-225 Bydgoszcz

${ }^{1}$ Katedra Entomologii i Fitopatologii Molekularnej

robert@utp.edu.pl

${ }^{2}$ Katedra Agrotechnologii 


\section{Wstęp / Introduction}

Kelpak jest preparatem otrzymywanym w procesie ciśnieniowej preparacji komórek roślinnych algi morskiej Enclonia maxima (Osbeck) (Erlichowski i Pawińska 2003). Ekstrakty z alg wykazują bardzo silne działanie biostymulujące poprzez zwiększanie tolerancji roślin na czynniki stresowe. Spośród nich najsilniejsze działanie regulujące wzrost i rozwój roślin wykazują brunatnice. Zawarte w nich fitohormony (auksyny, cytokininy, polifenole) wspomagają procesy przystosowywania się roślin do niekorzystnych warunków siedliskowych (Matysiak i Adamczewski 2009; Matysiak 2010). Efektem ich stosowania jest zwiększenie plonowania ziemniaków (Erlichowski i Pawińska 2003), rzepaku ozimego (Matysiak i Adamczewski 2005), kukurydzy, pszenicy jarej czy jęczmienia jarego (Matysiak i Adamczewski 2006).

Nieliczne badania i doniesienia naukowe, obserwacje praktyki rolniczej, a także informacje producentów biopreparatów wskazują na ich pozytywne oddziaływanie na procesy fizjologiczne zachodzące w roślinie uprawnej, ale także na ograniczenie presji towarzyszących jej fitofagów (Hankins i Hockey 1990; Matysiak i Adamczewski 2006). W wielu przypadkach brakuje naukowego wyjaśnienia mechanizmu tego oddziaływania. W zakresie fitofagicznej entomofauny można przypuszczać, że po stosowaniu bioregulatorów zachodzą w roślinie zmiany biochemiczne, polegające na zwiększonym wydzielaniu lotnych związków organicznych, odpowiadających za mechanizm wyboru i zasiedlania roślin (Piesik 2008). Przed szczegółowymi badaniami na poziomie biochemicznym konieczne jest naukowe potwierdzenie wpływu aplikacji ekstraktów $\mathrm{z}$ alg na liczebność fitofagów, szczególnie w okresach masowego ich występowania w warunkach polowej uprawy ważnych gospodarczo gatunków roślin.

Celem pracy była ocena wpływu stosowania bioregulatora Kelpak na liczebność szkodliwej entomofauny w pszenicy jarej w kolejnych fazach jej rozwoju, od strzelania w źdźbło do dojrzewania.

\section{Materiały i metody / Materials and methods}

Badania dotyczące wpływu bioregulatora Kelpak na entomofaunę zasiedlająca pszenice jarą były prowadzone w latach 2011-2012, na poletkach doświadczalnych Stacji Badawczej w Mochełku należących do Wydziału Rolnictwa i Biotechnologii Uniwersytetu TechnologicznoPrzyrodniczego w Bydgoszczy, w województwie kujawsko-pomorskim, na glebie klasy 4a.

Pszenicę jarą odmiany Katoda wysiewano na początku kwietnia, w ilości $230 \mathrm{~kg} / \mathrm{ha}$, w rozstawie rzędów $10,5 \mathrm{~cm}$, na głębokość $4 \mathrm{~cm}$. Przedsiewne nawożenie mineralne stosowano w dawkach: $80 \mathrm{~kg} / \mathrm{ha} \mathrm{N}, 70 \mathrm{~kg} / \mathrm{ha} \mathrm{P}, 80 \mathrm{~kg} / \mathrm{ha}$ K. Dodatkowe dawki azotu aplikowano dwukrotnie: na początku fazy strzelania w źdźbło $60 \mathrm{~kg} / \mathrm{ha}$ oraz po wykształceniu liścia flagowego dolistnie $9 \mathrm{~kg} / \mathrm{ha}$. Odchwaszczanie przeprowadzono przy użyciu herbicydu Lintur (180 g/ha), w fazie krzewienia pszenicy. Fungicydy aplikowano w fazie strzelania w źdźbło (Capalo 2 1/ha) i kłoszenia (Charizma 1,5 1/ha).

Liczebność odłowionej entomofauny w obiektach doświadczalnych porównano przy pomocy analizy dwuczynnikowej, w układzie losowych podbloków, w czterech powtórzeniach. Czynnikiem pierwszego rzędu był sposób aplikacji bioregulatora Kelpak: A1 - na początku krzewienia - 2 1/ha, A2 - po 1,5 1/ha w fazie krzewienia i strzelania w źdźbło, A3 - w fazie strzelania w źdźbło - 2 1/ha oraz $\mathrm{K}$ - kontrola (bez preparatu). Czynnikiem drugiego rzędu była faza rozwojowa pszenicy jarej: B1 - strzelanie w źdźbło, B2 - kłoszenie, B3 kwitnienie, B4 - dojrzałość mleczno-woskowa.

Owady odławiano metodą czerpakowania, cztery razy w sezonie wegetacyjnym: w drugiej dekadzie maja (faza strzelania w źdźbło), w pierwszej dekadzie czerwca (faza kłoszenia), w drugiej dekadzie czerwca (kwitnienie) oraz drugiej dekadzie lipca (dojrzałość mleczno-woskowa). W każdym z powtórzeń obiektu, o powierzchni $18 \mathrm{~m}^{2}$ wykonano po 9 uderzeń czerpakiem entomologicznym. Wyniki podano w sztukach na poletko - jako średnią z 4 powtórzeń. Entomofaunę oznaczono przy pomocy kluczy: Müller (1976), Korcz (1994), Zawirska (1994), Warchołowski (2003). Istotność różnic określono półprzedziałem ufności Tukeya przy poziomie istotności $\alpha=0,05$.

\section{Wyniki i dyskusja / Results and discussion}

$\mathrm{Na}$ podstawie przeprowadzonych obserwacji owady zaliczane do Hemiptera stanowiły najliczniejszą grupę (tab. 1). Szczyt ich liczebności przypadał na fazę kwitnienia pszenicy. Niezależnie od metody aplikacji preparatu Kelpak owadów tych odławiano mniej, w porównaniu do kontroli, w każdej fazie rozwojowej pszenicy jarej. Najbardziej liczna była Sitobion avenae (F.) H.R.L., szczególnie w fazie kwitnienia pszenicy. Biorąc pod uwagę średnią liczebność tej mszycy w całym badanym okresie rozwoju pszenicy jarej stwierdzono, że bioregulator Kelpak, niezależnie od dawki i terminu aplikacji wpłynął na zmniejszenie odłowu tego gatunku (tab. 1). Podobnie w fazie kłoszenia, kwitnienia i dojrzewania stosowanie bioregulatora było zawsze korzystne. W fazie strzelania w źdźbło liczebność tej mszycy była najmniejsza, a różnice $\mathrm{w}$ porównywanych obiektach nieistotne. W przeciwieństwie do mszycy zbożowej, Rhopalosiphum padi L. występowała w mniejszym nasileniu. Otrzymany w badaniach własnych udział i skład gatunkowy mszyc zbożowych na pszenicy potwierdzają Abo Kaf i Miczulski (1991). W fazie strzelania w źdźbło odławiano $R$. padi najwięcej, przy czym zastosowanie bioregulatora Kelpak, niezależnie od sposobu aplikacji powodowało zmniejszenie jej liczebności, w porównaniu do kontroli (tab. 1). Potwierdzają to wyniki przedstawione przez Stephenson (1966) oraz Hankins i Hockey (1990) którzy twierdza, że mszyce oraz inne odżywiające się sokami fitofagi, zazwyczaj unikają roślin traktowanych wyciągami z alg. Najczęściej odławianymi Miridae były zmieniki. Pluskwiaki te najliczniej zasiedlały pszenicę w dojrzałości mleczno-woskowej. W tej fazie rozwojowej 
Tabela 1. Liczebność pluskwiaków na pszenicy jarej po aplikacji bioregulatora Kelpak z lat 2011-2012 [szt./poletko] Table 1. Number of Hemiptera individuals on the spring wheat after using the bioregulator Kelpak in 2011-2012 [individuals per plot]

\begin{tabular}{|c|c|c|c|c|c|c|c|c|c|c|c|c|c|c|c|c|c|c|c|}
\hline \multirow{3}{*}{$\begin{array}{c}(\mathrm{A}) \\
\text { Metoda } \\
\text { aplikacji } \\
\text { Method of } \\
\text { application }\end{array}$} & \multicolumn{19}{|c|}{ (B) Faza rozwoju - Development stage } \\
\hline & B1 & B2 & B3 & B4 & $\begin{array}{l}\text { Śr } \\
M\end{array}$ & B1 & B2 & B3 & B4 & $\begin{array}{l}\dot{S} r \\
M\end{array}$ & B1 & B2 & B3 & $\begin{array}{l}\text { Śr } \\
M\end{array}$ & B1 & B2 & B3 & B4 & $\begin{array}{l}\mathrm{S} r \\
\mathrm{M}\end{array}$ \\
\hline & \multicolumn{5}{|c|}{$\begin{array}{l}\text { pluskwiaki razem* } \\
\text { Hemiptera total* }\end{array}$} & \multicolumn{5}{|c|}{$\begin{array}{c}\text { mszyca zbożowa } \\
\text { Sitobion avenae (F.) H.R.L. } \\
\text { (Aphididae) }\end{array}$} & \multicolumn{4}{|c|}{$\begin{array}{c}\text { mszyca czeremchowo- } \\
\text { zbożowa Rhopalosiphum } \\
\text { padi L. (Aphididae) }\end{array}$} & \multicolumn{5}{|c|}{$\begin{array}{l}\text { zmieniki } \\
\text { Lygus spp. } \\
\text { (Miridae) }\end{array}$} \\
\hline A1 & 10,00 & 15,25 & 30,75 & 29,75 & 21,44 & 0,75 & 4,75 & 23,50 & 4,88 & 8,47 & 2,63 & 1,25 & 1,00 & 1,63 & 1,50 & 1,63 & 1,13 & 6,38 & 2,66 \\
\hline 18 & 9,13 & 16,63 & 31,13 & 26,25 & 20,78 & (0,כ0 & 8,00 & 24,00 & 4,63 & 9,25 & 2,88 & $2,2 J$ & 0,00 & 1,88 & 0,00 & 0,00 & 75 & 4,88 & 1,04 \\
\hline A3 & 10,63 & 16,25 & 30,25 & 28,75 & 21,47 & 0,50 & 7,63 & 23,63 & 5,75 & 9,38 & 3,50 & 2,75 & 0,63 & 2,29 & 0,88 & 0,63 & 0,88 & 4,88 & 1,81 \\
\hline $\mathrm{K}-\mathrm{C}$ & 14,88 & 29,00 & 38,38 & 33,50 & 28,94 & 0,88 & 11,13 & 28,00 & 8,00 & 12,00 & 4,63 & 2,63 & 1,00 & 2,75 & 1,63 & 1,13 & 1,38 & 5,75 & 2,47 \\
\hline$r-M$ &, 16 & 19,28 & 32,63 & 29,56 & 23,16 & 0,63 & 7,88 & 24,78 & 5,81 & 9,77 & 3,41 & 2,22 & 0,78 & 2,14 & 1,22 & 1,06 & 1,03 & 5,47 & 2,20 \\
\hline $\begin{array}{l}\operatorname{NIR}(0,05) \\
\operatorname{SD}(0.05)\end{array}$ & \multicolumn{5}{|c|}{$\begin{array}{l}\mathrm{A}=1,22 ; \mathrm{B}=0,85 \\
\mathrm{~B} / \mathrm{A}=1,70 ; \mathrm{A} / \mathrm{B}=1,85\end{array}$} & \multicolumn{5}{|c|}{$\begin{array}{l}\mathrm{A}=0,72 ; \mathrm{B}=0,70 \\
\mathrm{~B} / \mathrm{A}=1,39 ; \mathrm{A} / \mathrm{B}=1,37\end{array}$} & \multicolumn{4}{|c|}{$\begin{array}{l}\mathrm{A}=0,48 ; \mathrm{B}=0,48 \\
\mathrm{~B} / \mathrm{A}=0,96 ; \\
\mathrm{A} / \mathrm{B}=0,94\end{array}$} & \multicolumn{5}{|c|}{$\begin{array}{l}\mathrm{A}=0,48 ; \mathrm{B}=0,33 \\
\mathrm{~B} / \mathrm{A}=0,66 ; \mathrm{A} / \mathrm{B}=0,72\end{array}$} \\
\hline
\end{tabular}

A1 - 2 1/ha na początku krzewienia - at the beginning of tillering, A2 - 1,5 1/ha w fazie krzewienia i 1,5 1/ha w fazie strzelania w źdźbło - at the tillering and shooting stage, A3 - 2 1/ha w fazie strzelania w źdźbło - at the shooting stage, K - C - kontrola - control, Śr - M - średnia - mean, B1 - strzelanie w źdźbło - shooting, B2 - kłoszenie - earing, B3 - kwitnienie - flowering, B4 - dojrzałość mleczno-woskowa - milk-dough stage

*średnia z 4 powtórzeń każdego obiektu - mean of 4 replications

Tabela 2. Liczebność przylżeńców na pszenicy jarej po aplikacji bioregulatora Kelpak z lat 2011-2012 [szt./poletko]

Table 2. Number of Thysanoptera individuals on the spring wheat after using the bioregulator Kelpak in 2011-2012 [individuals per plot]

\begin{tabular}{|c|c|c|c|c|c|c|c|c|c|c|c|c|c|c|c|c|c|c|c|}
\hline \multirow{3}{*}{$\begin{array}{c}(\mathrm{A}) \\
\text { Metoda } \\
\text { aplikacji } \\
\text { Method of } \\
\text { application }\end{array}$} & \multicolumn{19}{|c|}{ (B) Faza rozwoju - Development stage } \\
\hline & B1 & B2 & B3 & B4 & $\begin{array}{l}\text { Śr } \\
M\end{array}$ & B1 & B2 & B3 & B4 & $\begin{array}{l}\text { Śr } \\
M\end{array}$ & B1 & B2 & B3 & B4 & $\begin{array}{l}\text { Śr } \\
\mathrm{M}\end{array}$ & B2 & B3 & B4 & $\begin{array}{l}\mathrm{S} r \\
\mathrm{M}\end{array}$ \\
\hline & \multicolumn{5}{|c|}{$\begin{array}{l}\text { przylżeńce razem* } \\
\text { Thysanoptera total* }\end{array}$} & \multicolumn{5}{|c|}{$\begin{array}{l}\text { wciornastkowate } \\
\text { Thripidae }\end{array}$} & \multicolumn{5}{|c|}{$\begin{array}{l}\text { kwietniczkowate } \\
\text { Phlaeothripidae }\end{array}$} & \multicolumn{4}{|c|}{$\begin{array}{l}\text { larwy przylżeńców } \\
\text { Thysanoptera larvae }\end{array}$} \\
\hline $\mathrm{A} 1$ & 1,50 & 34,38 & 21,88 & 15,63 & 18,34 & 1,25 & 30,50 & 19,13 & 11,75 & 15,66 & 0,38 & 0,88 & 0,63 & 1,38 & 0,81 & 1,25 & 0,88 & 2,00 & 1,38 \\
\hline $\mathrm{A} 2$ & 2,00 & 29,00 & 26,75 & 19,63 & 19,34 & 1,50 & 25,88 & 22,63 & 14,63 & 16,16 & 0,50 & 0,88 & 1,13 & 1,63 & 1,03 & 1,13 & 1,50 & 2,88 & 1,84 \\
\hline $\mathrm{A} 3$ & 2,00 & 23,38 & 30,13 & 16,88 & 18,09 & 1,25 & 20,88 & 26,50 & 11,50 & 15,03 & 0,75 & 0,88 & 0,63 & 1,88 & 1,03 & 0,88 & 1,50 & 3,00 & 1,79 \\
\hline $\mathrm{K}-\mathrm{C}$ & 2,88 & 31,75 & 36,00 & 23,00 & 23,41 & 2,00 & 27,25 & 31,38 & 14,25 & 18,72 & 0,63 & 1,00 & 0,75 & 3,25 & 1,41 & 1,63 & 2,13 & 4,50 & 2,75 \\
\hline$\dot{S} r-M$ & 2,09 & 29,63 & 28,69 & 18,71 & 19,80 & 1,50 & 26,13 & 24,91 & 13,03 & 16,39 & \begin{tabular}{|l|}
0,56 \\
\end{tabular} & 0,91 & 0,78 & 2,03 & \begin{tabular}{|l|}
1,07 \\
\end{tabular} & 1,22 & 1,50 & 3,09 & 1,94 \\
\hline $\begin{array}{l}\operatorname{NIR}(0,05) \\
\operatorname{LSD}(0.05)\end{array}$ & \multicolumn{5}{|c|}{$\begin{array}{l}\mathrm{A}=1,24 ; \mathrm{B}=0,76 \\
\mathrm{~B} / \mathrm{A}=1,51 ; \mathrm{A} / \mathrm{B}=1,74\end{array}$} & \multicolumn{5}{|c|}{$\begin{array}{l}\mathrm{A}=1,18 ; \mathrm{B}=0,72 \\
\mathrm{~B} / \mathrm{A}=1,44 ; \mathrm{A} / \mathrm{B}=1,65\end{array}$} & \multicolumn{5}{|c|}{$\begin{array}{l}\mathrm{A}=0,34 ; \mathrm{B}=0,18 \\
\mathrm{~B} / \mathrm{A}=0,36 ; \mathrm{A} / \mathrm{B}=0,44\end{array}$} & \multicolumn{4}{|c|}{$\begin{array}{l}\mathrm{A}=0,31 ; \mathrm{B}=0,20 \\
\mathrm{~B} / \mathrm{A}=0,41 ; \mathrm{A} / \mathrm{B}=0,45\end{array}$} \\
\hline
\end{tabular}

A1 - 2 1/ha na początku krzewienia - at the beginning of tillering, A2 - 1,5 1/ha w fazie krzewienia i 1,5 1/ha w fazie strzelania w źdźbło - at the tillering and shooting stage, A3 - 2 1/ha w fazie strzelania w źdźbło - at the shooting stage, $\mathrm{K}-\mathrm{C}$ - kontrola - control, Śr - M - średnia - mean, B1 - strzelanie w źdźbło - shooting, B2 - kłoszenie - earing, B3 - kwitnienie - flowering, B4 - dojrzałość mleczno-woskowa - milk-dough stage

*średnia z 4 powtórzeń każdego obiektu - mean of 4 replications

pszenicy liczbę odłowionych Lygus spp. ograniczała dwukrotna aplikacja bioregulatora po $1,5 \mathrm{l} / \mathrm{ha} \mathrm{w}$ fazie krzewienia oraz $\mathrm{w}$ okresie strzelania w źdźbło, a także jednorazowy zabieg $\mathrm{w}$ dawce $2 \mathrm{l} / \mathrm{ha} \mathrm{w}$ drugim terminie.

Fitofagiczne przylżeńce stanowiły dość liczną grupę owadów zasiedlających pszenicę jarą (tab. 2). Dominowały one szczególnie $w$ fazie kłoszenia oraz kwitnienia pszenicy, ale dość dużo odławiano ich również w fazie dojrzałości mleczno-woskowej. Wszystkie testowane sposoby aplikacji bioregulatora Kelpak wpłynęły na zmniejszenie średniego odłowu Thysanoptera w badanym okresie rozwoju generatywnego pszenicy, w stosunku do obiektu kontrolnego. Dominującymi spośród omawianego rzędu owadów były wciornastkowate (Thripidae). Po zastosowaniu preparatu wykazano redukcję ich liczebności w fazie kwitnienia i dojrzałości mleczno-woskowej pszenicy jarej. W porównaniu do nich, kwietniczkowate oraz larwy przylżeńców były rzadziej odławiane. Szczyt ich liczebności przypadał na fazę dojrzałości mleczno-woskowej pszenicy. W tej fazie występowanie tych owadów było ograniczone przez aplikację preparatu Kelpak, niezależnie od terminu i dawki jego stosowania. Omawiane w badaniach własnych szkodniki zaliczane do rzędu przylżeńców są wymieniane przez licznych autorów jako ważne fitofagi w uprawach zbóż i traw (Jackowski i Hurej 2000; Szeflińska 2002). Brakuje jednak informacji dotyczących ich występowania w warunkach coraz szerzej stosowanych bioregulatorów w uprawach polowych roślin 
Tabela 3. Liczebność chrząszczy na pszenicy jarej po aplikacji bioregulatora Kelpak z lat 2011-2012 [szt./poletko]

Table 3. Number of Coleoptera individuals on the spring wheat after using the bioregulator Kelpak in 2011-2012 [individuals per plot]

\begin{tabular}{|c|c|c|c|c|c|c|c|c|c|c|c|c|c|c|c|c|c|}
\hline \multirow{3}{*}{$\begin{array}{c}\text { (A) } \\
\text { Metoda } \\
\text { aplikacji } \\
\text { Method of } \\
\text { application }\end{array}$} & \multicolumn{17}{|c|}{ (B) Faza rozwoju - Development stage } \\
\hline & B1 & B2 & B3 & B4 & $\begin{array}{l}\text { Śr } \\
M\end{array}$ & B1 & B2 & B3 & B4 & $\begin{array}{l}\text { Śr } \\
M\end{array}$ & B1 & B2 & B4 & $\begin{array}{l}\text { Śr } \\
M\end{array}$ & B2 & B3 & $\begin{array}{l}\text { Śr } \\
M\end{array}$ \\
\hline & \multicolumn{5}{|c|}{$\begin{array}{l}\text { chrzaszzcze razem* } \\
\text { Coleoptera total* }\end{array}$} & \multicolumn{5}{|c|}{$\begin{array}{c}\text { imago skrzypionki zbożowej } \\
\text { Oulema menalopa L. adults } \\
\text { (Chrysomelidae) }\end{array}$} & \multicolumn{4}{|c|}{$\begin{array}{c}\text { imago skrzypionki błękitek } \\
\text { Oulema cyanella Voet. } \\
\text { adults (Chrysomelidae) }\end{array}$} & \multicolumn{3}{|c|}{$\begin{array}{l}\text { larwy skrzypionek } \\
\text { Oulema spp. larvae } \\
\text { (Chrysomelidae) }\end{array}$} \\
\hline 1 & 0,50 & 13,13 & 11,50 & 20,00 & 16,28 & 16,00 & 10,75 & 0,13 & 1,88 & 7,19 & 0,00 & 0,50 & 0,25 & 0,25 & 0,50 & 11,25 & 5,88 \\
\hline 2 & 7,63 & 17,63 & 15,50 & 14,63 & 16,34 & 12,63 & 14,25 & 0,25 & 0,75 & 6,97 & 0,00 & 0,25 & 0,38 & 0,21 & 0 , & 14,25 & 7,25 \\
\hline A3 & 22,38 & 14,88 & 16,13 & 20,25 & 18,41 & 17,38 & 12,50 & 0,13 & 1,00 & 7,75 & 0,50 & 0,38 & 0,25 & 0,38 & 0,00 & 15,88 & 7,94 \\
\hline $\mathrm{K}-\mathrm{C}$ & 29,63 & 18,63 & 20,00 & 24,00 & 23,06 & 22,88 & 15,38 & 0,00 & 1,50 & 9,94 & 0,50 & 0,63 & 0,63 & 0,59 & 0, & 9,13 & 9,57 \\
\hline$\dot{S} r-M$ & 22,53 & 16,06 & 15,78 & 19,72 & 18,52 & 17,22 & 13,22 & 0,13 & 1,28 & 7,96 & 0,25 & 0,44 & 0,38 & 0,36 & 0,19 & 15,13 & 7,66 \\
\hline $\begin{array}{l}\operatorname{NIR}(0,05) \\
\operatorname{LSD}(0.05)\end{array}$ & \multicolumn{5}{|c|}{$\begin{array}{l}\mathrm{A}=1,36 ; \mathrm{B}=0,72 \\
\mathrm{~B} / \mathrm{A}=1,44 ; \mathrm{A} / \mathrm{B}=1,77\end{array}$} & \multicolumn{5}{|c|}{$\begin{array}{l}\mathrm{A}=0,76 ; \mathrm{B}=0,44 \\
\mathrm{~B} / \mathrm{A}=0,88 ; \mathrm{A} / \mathrm{B}=1,04\end{array}$} & \multicolumn{4}{|c|}{$\begin{array}{l}\mathrm{A}=0,20 ; \mathrm{B}=0,18 \\
\mathrm{~B} / \mathrm{A}=0,36 ; \mathrm{A} / \mathrm{B}=0,37\end{array}$} & \multicolumn{3}{|c|}{$\begin{array}{l}\mathrm{A}=0,92 ; \mathrm{B}=0,36 \\
\mathrm{~B} / \mathrm{A}=0,33 ; \mathrm{A} / \mathrm{B}=0,64\end{array}$} \\
\hline
\end{tabular}

A1 - 2 1/ha na początku krzewienia - at the beginning of tillering, A2 - 1,5 1/ha w fazie krzewienia i 1,5 1/ha w fazie strzelania w źdźbło - at the tillering and shooting stage, A3 - 2 1/ha w fazie strzelania w źdźbło - at the shooting stage, $\mathrm{K}-\mathrm{C}$ - kontrola - control, Ś - M - średnia - mean, B1 - strzelanie w źdźbło - shooting, B2 - kłoszenie - earing, B3 - kwitnienie - flowering, B4 - dojrzałość mleczno-woskowa - milk-dough stage

*średnia z 4 powtórzeń każdego obiektu - mean of 4 replications

rolniczych. Jedynie w testach szklarniowych, po zastosowaniu biopreparatów wykazano zwiększenie atrakcyjności roślin ogórka dla wciornastka zachodniego, przy czym autorki nie wykluczają, że na to zjawisko mógł mieć wpływ termin przeprowadzonych doświadczeń (Tomczyk i Kropczyńska-Linkiewicz 2010).

Colopterofaunę w sezonie wegetacyjnym odławiano najmniej licznie podczas kłoszenia i kwitnienia pszenicy jarej. Zastosowane bioregulatora skutkowało istotnym, w porównaniu do kontroli, zmniejszeniem średniej liczebności tych owadów w badanym okresie rozwoju pszenicy jarej (od strzelania w źdźbło do dojrzałości mleczno-woskowej) (tab. 3). Fitofagiczne skrzypionki były dość liczną grupą owadów zasiedlających pszenicę jarą. Należą one obecnie do najgroźniejszych szkodników zbóż (Walczak 2007). Niezależnie od terminu i dawki, średnio w badanych fazach rozwojowych pszenicy jarej bioregulator Kelpak ograniczał występowanie skrzypionek, w porównaniu do wariantu bez zabiegu (kontrola). W fazie strzelania $\mathrm{W}$ źdźbło skrzypionki zbożowej (imagines pokolenia zimującego) było najwięcej. W tym okresie rozwoju pszenicy największą redukcję ich liczby spowodowało dwukrotne stosowanie bioregulatora (po 1,5 1/ha w fazie krzewienia i w fazie strzelania w źdźbło). W fazie kłoszenia najmniej skrzypionki zbożowej odławiano po jednorazowym zastosowaniu preparatu $\mathrm{w}$ dawce 2 1/ha w fazie krzewienia. Larwy skrzypionek swój szczyt liczebności miały $\mathrm{w}$ fazie kwitnienia pszenicy jarej. Najmniej odławiano ich na poletkach, na których zastosowano Kelpak w dawce $2 \mathrm{l} / \mathrm{ha}$ w fazie krzewienia pszenicy. Matysiak i Adamczewski (2009) podają, że ekstrakty z alg podawane są roślinom głównie poprzez liście, a ich działanie w dużym stopniu uzależnione jest od dawki, częstości zabiegów oraz gatunku rośliny uprawnej.

Przeprowadzone badania w większości potwierdziły ograniczenie liczebności fitofagicznej entomofauny na pszenicy jarej po zastosowaniu bioregulatora Kelpak, co uzasadnia wykonanie dalszych testów biochemicznych, które dadzą podstawę pełnego zrozumienia stymulacji mechanizmów obronnych roślin traktowanych ekstraktami $\mathrm{z}$ alg.

\section{Wnioski / Conclusions}

1. Bioregulator Kelpak stosowany w dawce $21 /$ ha w fazie krzewienia lub strzelania w źdźbło pszenicy jarej, jak również po 1,5 1/ha w obu tych fazach, ograniczał całkowitą liczebność fitofagów zaliczanych do Thysanoptera - wciornastkowatych i kwietniczkowatych.

2. Występowanie pluskwiaków w okresie rozwoju generatywnego pszenicy jarej (od strzelania w źdźbło do dojrzałości mleczno-woskowej) było mniejsze po aplikacji bioregulatora Kelpak w każdym wariancie jego stosowania. Wczesna aplikacja preparatu (w fazie krzewienia pszenicy) ograniczała liczebność mszycy zbożowej, ale nie miała wpływu na zmieniki.

3. Zastosowanie bioregulatora Kelpak, niezależnie od terminu i dawki spowodowało zmniejszenie liczebności imagines skrzypionki zbożowej w okresie jej masowego pojawu, tj. od fazy strzelania w źdźbło do kłoszenia pszenicy, a następnie larw skrzypionek w fazie kwitnienia rośliny.

\section{Literatura / References}

Abo Kaf N., Miczulski B. 1991. Mszyce zbożowe (Homoptera, Aphididae) występujące w łanach pszenicy i jęczmienia w okolicach Lublina. Rocz. Nauk Rol. 21 (1/2): 103-110. 
Erlichowski T., Pawińska M. 2003. Biologiczna ocena preparatu Kelpak w ziemniaku. Prog. Plant Prot./Post. Ochr. Roślin 43 (2): 606-609.

Hankins S.D., Hockey H.P. 1990. The effect of a liquid seaweed extract from Ascophyllum nodosum (Fucales, Phaeophyta) on the twospotted red spider mite Tetranychus urticae. Hydrobiologia 204 (205): 555-559.

Jackowski J., Hurej M. 2000. Thrips (Thysanoptera) on cereal species mixtures in the Opole region, Poland. Pol. Pismo Entomol. 69 (3): 377-388.

Korcz A. 1994. Szkodliwe pluskwiaki z rzędu różnoskrzydłych (Heteroptera). s. 233-292. W: „Diagnostyka Szkodników Roślin i ich Wrogów Naturalnych" (J. Boczek, red.). SGGW, Warszawa, 327 ss.

Matysiak K. 2010. Regulatory wzrostu i rozwoju roślin. Agrotechnika 1: 18-19.

Matysiak K., Adamczewski K. 2005. Ocena działania regulatorów wzrostu w rzepaku ozimym. Prog. Plant Prot./Post. Ochr. Roślin 45 (2): 898-901.

Matysiak K., Adamczewski K. 2006. Wpływ bioregulatora Kelpak na plonowanie roślin uprawnych. Prog. Plant Prot./Post. Ochr. Roślin 46 (2): 102-108.

Matysiak K., Adamczewski K. 2009. Regulatory wzrostu i rozwoju roślin - kierunki badań w Polsce i na świecie. Prog. Plant Prot./Post. Ochr. Roślin 49 (4): 1810-1816.

Müller F.P. 1976. Mszyce - Szkodniki Roślin. Terenowy Klucz do Oznaczania. PWN, Warszawa, 119 ss.

Piesik D. 2008. Wpływ żerowania larw i chrząszczy skrzypionki zbożowej (Oulema melanopus L., Coleoptera: Chrysomelidae) na wydzielanie lotnych związków organicznych przez pszenicę (Triticum aestivum L. emend. Fiori et Paol.) oraz reakcja imagines na te komponenty. Rozprawa habilitacyjna 131. UT-P, Bydgoszcz, 88 ss.

Stephenson W.M. 1966. The effect of hydrolyzed seaweed on certain plant pests and diseases. Proc. Int. Seaweed Symp. 5: 405-415.

Szeflińska D. 2002. Znaczenie wciornastków Thysanoptera sp. w uprawach zbóż w Polsce. Post. Nauk Rol. 5: 59-64.

Tomczyk A., Kropczyńska-Linkiewicz D. 2010. Efektywność drapieżnych roztoczy na roślinach ogórka traktowanych induktorami odporności roślin i biostymulatorami. Prog. Plant Prot./Post. Ochr. Roślin 50 (1): 361-364.

Walczak F. 2007. Groźne szkodniki zbóż i metody ich zwalczania. Ochrona Roślin 6: 22-27.

Warchałowski A. 2003. Chrysomelidae. The Leaf beetles of Europe and the Mediterranean area. Natura Optima Dux, Warszawa, 600 ss.

Zawirska I. 1994. Wciornastki (Thysanoptera). s. 145-174. W: „Diagnostyka Szkodników Roślin i ich Wrogów Naturalnych” (J. Boczek, red.). SGGW, Warszawa, 327 ss. 